\title{
Teknoloji destekli öğretim materyalleri WebQuestlerin yeterliklerini yordayan değişkenler
}

\author{
Mevhibe KOBAK-DEMIR*, Hülya GÜR \\ Balıkesir Üniversitesi Necatibey Eğitim Fakültesi, Matematik ve Fen Bilimleri Eğitimi, Balıkesir. \\ Geliş Tarihi (Recived Date): 27.04.2017 \\ Kabul Tarihi (Accepted Date): 13.10.2017
}

\section{Özet}

Bu çalışma öğretmen adaylarının tasarladıkları WebQuest etkinliklerinin yeterliklerini yordayan değişkenlerin belirlenmesini amaçlayan korelasyonel bir araştırmadır. Modele dahil edilen değişkenlerden WebQuest etkinliklerinin yeterlikleri yordanan (bă̆ımlı) değişken; öğretimde WebQuest kullanmaya yönelik algı, akademik başarı ve bilgi ve iletişim teknolojileri kullanımı seviyesi, yordayan (bă̆ımsız) değişkenler olarak ele alınmıştır. Araştırma bir devlet üniversitesinin ortaöğretim matematik öğretmenliği bölümünde öğrenim gören 74 öğretmen adayı ile yürütülmüşsür. Çalışmanın amacı doğrultusunda öğretmen adaylarının matematik öğretim programında yer alan kazanımlara uygun olarak hazırladıkları WebQuestler, "WebQuest Değerlendirme Tablosu (Rubric)" ile değerlendirilmiştir. Veriler fakülte kayıtları, Matematik Öğretiminde WebQuest Kullanmaya Yönelik Algl Ölçeği" ve "Bilgi ve İletişim Teknolojileri Kullanım Seviyeleri Ölçeği" ile toplanmıştır. Verilerinin analizinde regresyon analizi tekniği kullanılmıştır. Araştırma sonunda, öğretmen adaylarının tasarladıkları WebQuest etkinliklerinin yeterliklerinin \%53.5'ini bilgi ve iletişim teknolojileri kullanımı seviyeleri ile açıklandığı sonucuna ulaşılmıştır.

Anahtar kelimeler: WebQuest, materyal geliştirme, regresyon analizi, matematik eğitimi

\footnotetext{
* Mevhibe KOBAK-DEMIR, mevhibekobak@balikesir.edu.tr, http://orcid.org/0000-0001-6614-4101 Hülya GÜR, hgur@balikesir.edu.tr, http://orcid.org/0000-0001-8479-8811
} 


\title{
The predictor variables of qualification for technologic-supported instructional materials WebQuests
}

\begin{abstract}
This study aims to determine the variables predicting the WebQuest activities prepared by the pre-service teachers, is a correlational research model. The variables included in the model are considered the adequacy of WebQuest activities as a predicted (dependent) variable; the perception of using WebQuests in teaching, academic achievement and the knowledge related Web based mathematics teaching as predictor (independent) variables. The study has been conducted by 74 pre-service mathematics teachers studying at the State University, Secondary Science and Mathematics Education-Mathematics Education Department. For this study's purpose, WebQuestler, prepared according to the achievements in the mathematics curriculum, is assessed by the "WebQuest Evaluation Table (Rubric)". Data were collected by faculty registers, the WebQuest Perceptions Scale in Mathematics Teaching, and the Information and Communication Technology Usage Levels Scale. In the data analysis, regression analysis has been used. At the end of the research, 53.5\% of the qualifications of the WebQuest activities designed by the prospective teachers were reached with information and communication technology utilization levels.
\end{abstract}

Keywords: WebQuests, developing material, regression analysis, mathematics education

\section{Giriş}

Teknolojinin hızla yayılmasıyla birlikte öğretim ortamında etkin kullanılmasıyla ilgili beklentiler de her geçen gün artış göstermektedir [1]. Teknoloji, eğitimde ilerlemeyi sağlamak için önemli bir role sahiptir. Eğitimcilerin de bu kapsamda teknolojiyi kendi çalışma alanlarıyla birleştirmeleri yani eğitime bu teknolojileri entegre etmeleri gerekmektedir [2]. Ancak etkili bir entegrasyon süreci çok boyutlu ve dinamik bir süreçtir. $\mathrm{Bu}$ süreç beraberinde eğitim politikaları, öğretim programı, öğretmen yeterlikleri, öğrenci öğrenmesi gibi hem sistem hem de bireye özgü pek çok değişkeni kapsar. Bu durum sürecin modellenme çalışmalarına da yansımış durumdadır [3]. Öğrenme öğretme sürecine teknolojinin entegrasyonu konusunda süreci açıklamaya yönelik "teknolojik pedagojik alan bilgisi" (TPACK) [4] en fazla yararlanılan modeldir [5]. Literatürde bu kavram teknolojik pedagojik içerik bilgisi olarak da adlandırılmaktadır.

Mishra ve Kohler (2006) [4] tarafından ilk defa tanımlanan Teknolojik Pedagojik İçerik Bilgisi (TPİB) Shulman (1986) [6] tarafından öne sürülen Pedagojik İçerik Bilgisi (PİB) kavramına teknoloji boyutunun eklenmesi sonucu ortaya çıkmıştır. TPİB öğretmenin teknolojiyi pedagojik açıdan nasıl kullanacağını tanımlayan bir kavramdır [7]. Bu modelde içerik bilgisi pedagoji bilgisi ve teknoloji bilgisi olmak üzere 3 temel bileşen ile bu temel bileşenlerin birleştirilmesiyle oluşan pedagojik içerik bilgisi, teknolojik içerik bilgisi, teknolojik pedagoji bilgisi ve teknolojik pedagojik içerik bilgisi şeklinde 7 unsurdan oluşmaktadır. Modelin yapısı aşağıdaki şekilde verilmiştir [8]: 
Gelişen teknolojiyle birlikte web tabanlı öğretim teknolojilerinin de yaygınlaşması; teknolojik pedagojik içerik bilgisinin de yeniden yapılandırılmasını gerektirmiştir. Lee ve Tsai (2010) [9] teknolojik pedagojik içerik bilgisine Web'le öğretim kısmını ekleyerek Web-destekli teknolojik pedagojik içerik bilgisi (Web-TPİB) modelini oluşturmuşlardır. Bu model içerik, pedagojik ve web bilgisi olmak üzere üç temel bileşen üzerine kurulmuştur. Ayrıca model bu temel bileşenlerin bir araya gelmesi ile oluşan Pedagojik İçerik Bilgisi, Web İçerik Bilgisi, Web Pedagoji Bilgisi ve Web Pedagojik İçerik Bilgisi unsurlardan oluşmaktadır:

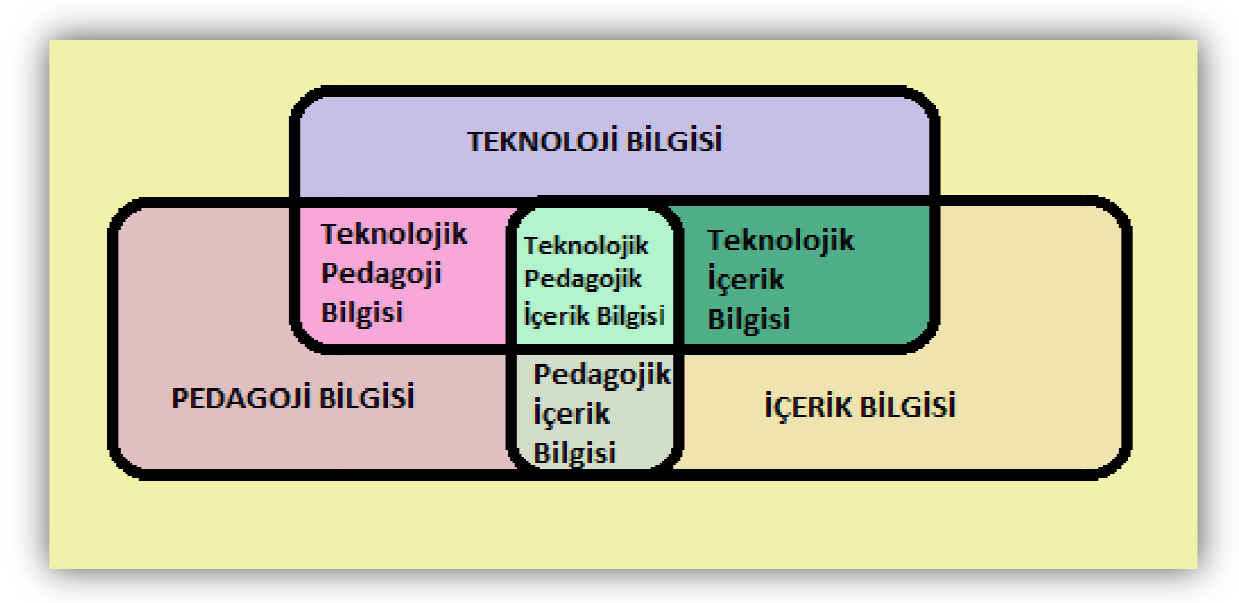

Şekil 1. TPİB modeli çerçevesi ve bilgi bileşenleri.

Pedagojik içerik bilgisi: Pedagojik içerik bilgisi, ilgili alanda öğrenme ve öğretme aktivitelerinin daha verimli olabilmesi için içerik bilgisinin yapısına göre geliştirilen pedagojik yaklaşımdır [13].

Web içerik bilgisi: Konu alanıyla ilgili Web'in sahip olduğu avantajlar ve özelliklerin anlaşılmasını içeren bilgidir. Web içerik bilgisinde öğretmen/öğretmen adayları sadece içeriği bilmekle kalmaz, web uygulamalarına içeriğin entegre edilmesinin yollarını da bilir.

Web pedagoji bilgisi: Öğretmenlerin eğitim ortamlarında kullandıkları Web'in olanakları ve bileşenlerinin bilgisini içerir.

Web pedagojik içerik bilgisi: Web ile öğretim bilgisidir.

Bireylerin iletişim kurmalarının yanı sıra bilgiye ulaşma ve paylaşmalarında kullanılan kaynakların başında internet gelmektedir. Ancak internette değerli bilgi siteleri mevcut olmasına rağmen, öğrenenlerin kavram karmaşası yaşamasına, bilgileri organize etmede ve doğru bilgiye ulaşmakta zorluklar yaşanmasına neden olan birçok eksik, yanlış ve faydasız bilgiler içeren web siteleri bulunmaktadır [11]. Örneğin çoğu zaman hatalı bilgiler içeren, doğruluğu kontrol edilmeden isteyen herkesin içerik ekleyebildiği vikipedi gibi. $\mathrm{Bu}$ siteler arama yaparken öğretim hedefine uygun olmayan seçeneklerden uygun olanlarını bulmak konuya odaklanmayı engellemekte ve zaman kaybına neden olmaktadır [12]. Tüm bu olumsuzlukları ortadan kaldırmak için internetin eğitim öğretim faaliyetlerinde kullanılması yönünde çeşitli yaklaşımlar geliştirilmiştir. Bunlardan biri de WebQuestlerdir. İngilizce Web (ağ) ve Quest (sorgulama) kelimelerinden türetilen WebQuest Türkçede ağ araştırması [15], Web macerası [16, 17], ağ soruşturması [18] gibi isimlerle anılmaktadır. 
Şekil 2'de Web-TPİB modelinin yapısı ve bileșenleri yer almaktadır [10]:

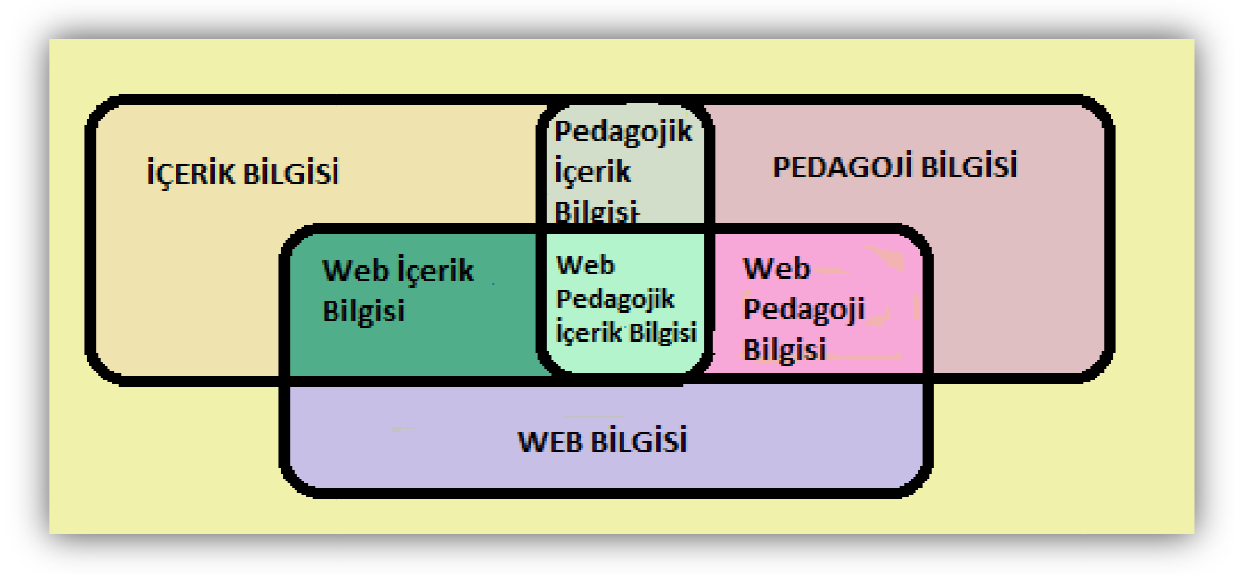

Şekil 2. Web-TPİB modeli çerçevesi ve bilgi bileşenleri.

WebQuest "öğrencilerin birbiriyle etkileşim halinde çalıştıkları, bilgilerin tamamının veya büyük bir kısmının internet kaynaklarından edinildiği, öğrencinin zamanı en iyi şekilde kullanımı için tasarlanmış olan araştırma odaklı veya araştırmaya dayalı öğrenme aktivitesidir” [14]. Bu çalışmada ise WebQuest ifadesi kullanılacaktır.

Bir WebQuest; giriş (introduction), işlem/görev (task), süreç (process), bilgi kaynakları (information sources), değerlendirme (evaluatian) ve sonuç (conclusion) olmak üzere en az 6 bölümden oluşmaktadır. Giriş bölümünde çalışma ve etkinlik çekici veya ilginç bir senaryo/hikaye ile sunularak öğretmen ve öğrencilere neler yapılacağı hakkında bilgi verilir [11]. Görev, WebQuestin en önemli bölümüdür. Çünkü bu bölümde öğretim programındaki kazanımlar somut olarak ifade edilir [35]. Bölümde öğrenciye verilmek istenen veya öğrencinin kazanması gereken bilgi çocuk için anlamlı, yapılabilir, ilginç ve eğlenceli bir görevle sunulur. Süreç öğrencinin hedefe ulaşabilmesi için gerekli bilgi ve yönergelerin yer aldığg bölümdür [19]. Bu kısımda grup üyelerinin etkinlikteki rolü araştırmayı nasıl organize edecekleri, yapılması gerekenler ve öğrencilerin görevi tamamlamak için geçecekleri basamaklar detaylı bir şekilde açıklanır [12]. Öğrencinin görevi tamamlayabilmesi için öğretmen tarafından hazırlanmış/seçilmiş kaynakların listesi kaynaklar bölümünde yer alır [19]. Kaynaklar ayrı bir bölüm olabileceği gibi süreç bölümü içerisinde de verilebilir [20]. Değerlendirme, öğrencinin yapmış olduğu çalışma, kazandığı bilgi veya ulaştığı noktanın nasıl değerlendirileceğinin açıklandığı bölümdür. Sonuç bölümünde öğrencinin ne öğrendiği/öğrenmesi gerektiği hatırlatılır, öğrencinin deneyim kazanması, bilgilerini geliştirme ve uygulaması için yardım edilir [19].

Türkçe WebQuestlerin sınırlı sayıda olması ve var olan WebQuestlerde ise sitelerin güvenilir olmaması, öğrencinin bilişsel seviyesine ve kazanımlara uygun olmaması WebQuest etkinliklerinin öğretimde kullanımını zorlaştırmaktadır [21]. Bu nedenle öğretmenlerin bu teknolojileri öğretimlerine entegre etmesinin yanı sira nitelikli materyaller geliştirmesinin önem taşıdığı söylenebilir. Teknolojinin öğrenme öğretme sürecine uyarlanmasında teknolojik alt yapı, kurumsal destek ve kültürel ve sosyal etki (toplumsal değer, kültürel faktörler, sosyal sistem) gibi kurumsal faktörlerin yanı sıra bireylerin bilgisayar yeterlikleri ve teknolojinin yararına ilişkin algıları gibi bireysel faktörler etkili olmaktadır [22-28]. Diğer bir deyişle kurumların teknolojiyle ilgili alt yapısının sağlanması, onun öğretmenler tarafından benimseneceği ve öğrenme ortamına uyarlanacağı anlamına gelmemektedir [22]. Eğitim öğretime ve yeni teknolojilerin 
yaygınlaşmasına yön verecek olan öğretmenlerin kullanılacak teknolojilere ilişkin algılarını belirlemek etkili bir teknoloji entegrasyonu sağlamak açısından faydalı olacaktır. Ayrıca öğretimi etkili hale getirmek için gerekli öğretmen niteliklerinin başında materyal üretme ve kullanma gelmektedir [29]. Öğretmenlerin, bir materyali öğretimlerinde kullanmaya yönelik algıları, geliştirdikleri materyallerin yeterliklerini nitelikli olmasını etkileyecektir.

Eğitim fakültelerinin lisans programlarının ilk yıllarında öğrencilere bilgisayar okuryazarlığı sağlanmakta ve birbirinden bağımsız bir şekilde genel kültür, konu alanı ve öğretmenlik meslek bilgilerini verilmekte, son sınıfa geldiklerinde ise bu bilgilerini bütünleştirmeleri ve edindikleri bilgilerle öğretim teknolojilerini kullanmaları ve materyal geliştirmeyi öğrenmeleri sağlanmaktadır [32,33]. Alınan hizmet içi eğitimler öğretmen adaylarının öğretmenlik becerileriyle teknolojiyi birleştirmelerinde önemli bir rol oynamaktadır [34]. Yapılan çalışmalar, öğretmen adaylarının teknolojik pedagojik içerik bilgilerinin arttırılmasında eğitim fakültelerinde verilen eğitimin önemini ortaya koymaktadır. Kundu ve Brain (2006) WebQuest tasarlama etkinliklerinin, gelecekteki öğretim yöntemlerine teknolojiyi entegre etmeleri için öğretmen adaylarını hazırlamaları gerektiğini ifade etmektedir [36].

Teknolojinin hızlı gelişimi, teknoloji ile büyüyen günümüz kuşağı, eğitimin teknolojik materyallerle entegre bir şekilde ilerlemesini gerekli kılmaktadır. Öğretmenlerin teknolojiyi öğretimlerine entegre etmelerinin yanı sıra teknolojik materyalleri geliştirme konusunda yeterli hale gelmeleri de kaçınılmaz olmuştur. Araştırma sonuçları, materyal geliştirmede bilgi ve iletişim teknolojileri kullanımı seviyesinin önemli olduğunu göstermektedir. Bireylerin bilgi ve iletişim teknolojileri kullanımı seviyesinin ve buna bağlı olarak materyal geliştirme yeterliklerinin geliştirilmesinde hizmet öncesi ve hizmet öncesi eğitimlerin önemli rolü vardır. Verilen hizmet içi ve öncesi eğitimlerin bu konudaki yeterliklerinin incelenmesi alanyazına katkı sağlayacaktır.

Mevcut programlarda, öğretmen adaylarının, bu konudaki farkındalıklarını arttırmak için Öğretim Teknolojisi ve Materyal Tasarımı gibi meslek dersleri sunulmaktadır [44]. Öğretim Teknolojisi ve Materyal Tasarımı dersinin kapsamında öğretmen adaylarına öğrenme-öğretme süreçlerinde teknolojiyi kullanabilme, öğretim teknolojilerini kullanarak öğretim materyali geliştirme; var olan öğretim materyallerini değerlendirme becerileri kazandırılmaya çalışılmaktadır [45]. Ancak yapılan çalışmalar öğretmenlerin öğretim teknolojisi ve materyal kullanımı konusunda zorluk çektiğini göstermektedir [44, 46]. Özellikle öğretmen adayları öğretim amaçlı basit materyalleri hazırlama konusunda kendilerini yeterli görürken karmaşık ve çok amaçlı öğretim cihazlarını hazırlamada sıkıntı çekmektedirler [47].

$\mathrm{Bu}$ nedenle araştırmada gelecek nesilleri yetiştirecek olan öğretmen adaylarının matematik öğretiminde WebQuest kullanmaya yönelik algıları, akademik başarıları ve bilgi ve iletişim teknolojileri kullanım seviyelerinin, tasarladıkları WebQuest etkinliklerinin hangi faktörlerden etkilendiklerini araştırma bir ihtiyaç olarak görülmüştür. Araştırmada öğretmen adaylarının tasarladıkları WebQuestlerin yeterliliklerine odaklanılmış, uygulama becerileri ölçülmemiştir. $\mathrm{Bu}$ amaç doğrultusunda aşağıdaki sorulara cevap aranmıştır:

Öğretmen adaylarının matematik öğretiminde WebQuest kullanmaya yönelik algıları, akademik başarıları ve bilgi ve iletişim teknolojileri kullanım seviyeleri değişkenleri a) 
ayrı ayrı b) birlikte tasarlanan WebQuest etkinliklerinin yeterliklerinin ne kadarını yordamaktadır?

\section{Yöntem}

$\mathrm{Bu}$ çalışma öğretmen adaylarının tasarladıkları WebQuest etkinliklerinin yeterliklerini yordayan değişkenlerin belirlenmesini amaçlayan korelasyonel bir araştırmadır. Korelasyonel araştırmalar iki yada daha çok değişken arasındaki ilişkinin, herhangi bir şekilde bu değişkenlere müdahale edilmeden incelendiği araştırmalardır. Bu araştırmalar, değişkenler arasındaki ilişkilerin açığa çıkarılmasında, bu ilişkilerin düzeylerinin belirlenmesinde etkili ve bu ilişkilerle ilgili daha üst düzey araştırmaların yapılması için gerekli ipuçlarını sağlar [37]. Modele dahil edilen değişkenlerden WebQuest yeterlikleri yordanan (bağımlı) değişken; öğretimde WebQuest kullanmaya yönelik algı, akademik başarı ve bilgi ve iletişim teknolojileri kullanım seviyelerine ilişkin bilgileri yordayan (bağımsız) değişkenler olarak ele alınmıştır.

Araştırma Marmara Bölgesindeki bir devlet üniversitesinin matematik öğretmenliği bölümü son sınıfında öğrenim gören 74 öğretmen adayı ile yürütülmüştür. Katılımcıların 47'si kadın, 27'si erkektir. Öğretmen adayları lisans eğitimi süresince teknoloji kullanımına yönelik; Algoritmalar ve Programlama (3+0), OFFICE Uygulamaları (2+0), FLASH Uygulamaları (2+0), C Programlama Dili (2+0), Öğretim Teknolojileri ve Materyal Tasarımı (2+2), Matematik Eğitiminde İnternet Uygulamaları (4+0) derslerini almışlardır. Öğretmen adaylarından her biri Ortaöğretim Matematik Dersi $(9,10,11$ ve 12 . Sinıflar) öğretim programında yer alan kazanımlara uygun olarak WebQuest tasarlamış, bu WebQuestlerin yeterlikleri Bellofatto, Bahl, Casey, Krill ve Dodge (2001) [38] tarafından hazırlanan ve Asker (2005) [39] tarafından Türkçeye uyarlanan "WebQuest Değerlendirme Tablosu (Rubric)" ile değerlendirilmiştir.

Öğretmen adaylarının akademik başarıları fakülte kayıtlarından elde edilmiştir. Bilgi ve İletişim teknolojileri kullanım seviyelerinin belirlenmesinde Kutluca, Arslan ve Özpınar (2010) [40] tarafından geliştirilen 30 maddelik ölçek kullanılmıştır. Öğretmen adaylarının matematik öğretiminde WebQuest kullanmaya yönelik algılarına ilişkin verileri toplamak amaciyla 38 maddeden oluşan Kobak-Demir ve Gür (2016) [41] tarafından geliştirilen ölçekten yararlanılmıştır. Araştırma verileri, regresyon analizi tekniği kullanılarak analiz edilmiştir.

\section{Bulgular ve yorum}

$\mathrm{Bu}$ bölümde öğretmen adaylarının WebQuest tasarlama etkinliklerinin yeterliliklerinin yordayıcısı olarak ele alınan değişkenlere ilișkin veriler üzerinde yapılan regresyon analizi sonuçları tablolar halinde verilmiştir. Araştırma verileri analiz edilmeden önce yordanan değişkene ilişkin histogram ve normal dağılım eğrisi oluşturulmuş verilerin dağılımının normale yakın olduğu gözlenmiştir.

Öğretmen adaylarının hazırladıkları WebQuest etkinlikleri, "WebQuest Değerlendirme Tablosu (Rubric)" ile incelenmiştir. Bu değerlendirme tablosunda Genel çekicilik (8 puan), Giriş (4 puan), Görev (10 puan), Süreç (14 puan), Kaynaklar (8 puan) ve değerlendirme (6 puan) ayrı başlıklar altında değerlendirilmiştir. Her bir başlık altında 
hazırlanan WebQuestin yeterliliği yeni başlayan, gelișen ve başarılı olarak 3 farklı ölçüt baz alınarak incelenmiştir. Örneğin, Giriş bölümü, motivasyonal etkililiği ve bilişsel etkililiği açısından değerlendirilmektedir. Eğer bir WebQuestte giriş bölümü, okuyucuyu sonraki bölümlere hazırlamıyor, yada öğrenenin hali hazırda bildiği konular üzerine kurulmuş ise incelenen WebQuestin bilişsel etkililiği 0 puan (yeni başlayan)'dır. Eğer giriş bölümü öğrenenin önceki bilgilerine gönderme yapıyor ve belirli ölçüde dersin ne hakkında olduğu konusunda onlara fikir veriyor ise 1 puan (Gelişen), öğrencilerin ön bilgilerinin üzerine ilave edilerek kurulmuş ve onları dersin ne hakkında olduğu konusunda bir izlenim edinmelerini sağlayarak derse hazırlıyorsa WebQuestin giriș bölümünün bilişsel etkililiğinden alabileceği puan 2 puan (başarılı)'dır. Ek 1 'de örnek WebQuest yer almaktadır. Öğretmen adaylarının hazırladıkları WebQuest etkinlikleri 50 puan üzerinden değerlendirilmiş, alınan puanlara ilişkin betimsel istatistikler tablo 1'de sunulmuştur:

Tablo 1. Öğretmen adaylarının WebQuest etkinliklerinden aldıkları puanlara ilişkin betimsel istatistikler.

\begin{tabular}{cccccc}
\hline & $\mathrm{N}$ & Minimum & Maksimum & $\overline{\mathrm{X}}$ & ss \\
\hline Alınan Puanlar & 74 & 33.00 & 47.00 & 43.07 & 3.71 \\
\hline
\end{tabular}

Tablo 1 incelendiğinde araştırmaya katılan 74 öğretmen adayının WebQuest etkinliklerinden aldıkları puanların ortalamasının 43.07, standart sapmasının 3.71 olduğu söylenebilir. Öğretmen adaylarının aldıkları en düşük puan 33, en yüksek puan ise 47 'dir.

Öğretmen adaylarının matematik öğretiminde WebQuest kullanmaya yönelik algıları, akademik başarıları ve bilgi ve iletişim teknolojileri kullanım seviyelerine ilişkin her bir değişkenin tasarlanan WebQuest etkinliklerinin yeterliklerini yordama gücünü tespit etmek amacıyla basit doğrusal regresyon analizi yapılmış, sonuçlar Tablo 2`de sunulmuştur.

Tablo 2 incelendiğinde bilgi ve iletişim teknolojilerini kullanım seviyelerine ilişkin varyans seviyesinin $\left(F_{b t}\right.$ kul.seviye $\left.=76.159\right) \mathrm{p}<0.05$ anlamlılık seviyesinde anlamlı olduğu, WebQuest kullanımına yönelik algı ve akademik başarının ise anlamlı olmadığı görülmektedir. Varyans analizi sonuçlarının anlamlı olması, bağımsız değişkenin bağımlı değişkeni pozitif yönde $(\mathrm{R}=7.17)$ ve anlamlı yordadığını göstermektedir. Değişkenler tek başına incelendiğinde tasarlanan WebQuestlerin yeterliliklerini \%51.4'ünün bilgi ve iletişim teknolojileri kullanım seviyesi tarafından yordandığını göstermektedir $(\mathrm{R}=0.717)$.

Araştırmanın ikinci alt probleminde bağımsız değişkenlerin birlikte WebQuest etkinliklerini yordama gücü araştırılmıştır. Bu probleme yanıt aramak için WebQuest kullanmaya yönelik algıları, akademik başarıları ve bilgi ve iletişim teknolojileri kullanım seviyelerinin WebQuest etkinliklerinin yeterliklerini yordama derecesine ilişkin çoklu regresyon analizi yapılmış ve sonuçlar Tablo 3'de sunulmuştur: 
Tablo 2. Bağımsız değişkenlerin her birinin tek başına WebQuest etkinliklerinin yeterliklerini yordama gücüne ilişkin basit doğrusal regresyon analizi sonuçları.

\begin{tabular}{|c|c|c|c|c|c|c|c|c|}
\hline 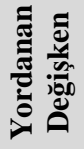 & $\begin{array}{c}\text { Yordayıcı } \\
\text { Değișkenler }\end{array}$ & $\begin{array}{c}\text { Regresyon } \\
\text { Katsayıs } \\
(\beta)\end{array}$ & St. Hata & $\mathbf{R}$ & $\mathbf{R}^{2}$ & $\begin{array}{c}\text { Standardize } \\
\text { edilmiş } \beta\end{array}$ & $\mathbf{t}$ & $\mathbf{F}$ \\
\hline \multirow{3}{*}{ 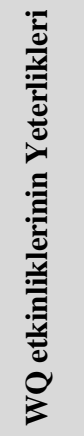 } & WQ kul.alg1 & -0.166 & 1.399 & 0.014 & 0.00 & -0.014 & -0.119 & 0.014 \\
\hline & $\begin{array}{l}\text { Akademik } \\
\text { başarı }\end{array}$ & 1.029 & 0.860 & 1.40 & 0.019 & 0.140 & 1.196 & 1.430 \\
\hline & $\begin{array}{l}\text { BT Kul. } \\
\text { Seviyeleri }\end{array}$ & 7.371 & 0.845 & 0.717 & 0.514 & 0.717 & 8.727 & $76.159^{*}$ \\
\hline
\end{tabular}

$\mathrm{N}=74 ; * \mathrm{p}<0.05$.

Tablo 3. Bağımsız değişkenlerin birlikte WebQuest etkinliklerinin yeterliklerini yordama gücüne ilişkin çoklu regresyon analizi sonuçları.

\begin{tabular}{|c|c|c|c|c|c|}
\hline $\begin{array}{l}\text { Yordanan } \\
\text { Değişken }\end{array}$ & $\begin{array}{c}\text { Yordayıcı } \\
\text { Değişkenler }\end{array}$ & $\begin{array}{c}\text { Regresyon } \\
\text { Katsayısı }(\beta) \\
\end{array}$ & St. Hata & $\begin{array}{c}\text { Standardize } \\
\text { edilmiş } \beta\end{array}$ & $\mathbf{t}$ \\
\hline \multirow{4}{*}{ 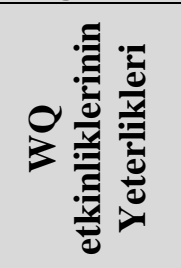 } & Sabit & 15.507 & 5.604 & & $2.767^{*}$ \\
\hline & WQ kul.alg1 & -1.647 & 0.982 & -0.139 & -1.677 \\
\hline & $\begin{array}{c}\text { Akademik } \\
\text { başarı }\end{array}$ & 0.319 & 0.607 & 0.043 & 0.525 \\
\hline & $\begin{array}{l}\text { BT Kul. } \\
\text { Seviyeleri }\end{array}$ & 7.551 & 0.858 & 0.734 & $8.798 *$ \\
\hline \multicolumn{6}{|c|}{$\mathrm{R}=0.731$} \\
\hline
\end{tabular}

Tablo 3'de görülen varyans analizi sonucunun $\mathrm{p}<0.05$ düzeyinde anlamlı olması, değişkenlerin WebQuest etkinliklerinin yeterliliklerine ilişkin açıkladığı varyansın istatistiksel olarak anlamlı olduğunu göstermektedir. Analiz sonucuna göre WebQuest kullanımına yönelik algı, akademik başarı ve bilgi ve iletişim teknolojileri kullanım seviyeleri birlikte ele alındığında değişkenlerin birlikte öğretmen adaylarının hazırladıkları WebQuest etkinliklerinin yeterlikleri ile anlamlı bir ilişki $(\mathrm{R}=0.731$, $\left.\mathrm{R}^{2}=0.535\right)$ sergilemektedir $(\mathrm{F}=26.792, \mathrm{p}<0.05)$. Değişkenler birlikte, WebQuestlerin yeterlik puanlarındaki değişimin \%53.5'ini açıklamaktadır. Çoklu regresyon modelindeki parametreler incelendiğinde standardize edilmiş regresyon katsayıları $(\beta)$ yordayıcı değişkenlerin öğretmen adaylarının hazırladıkları WebQuest yeterlikleri üzerindeki önem sırasının, bilgi ve iletişim teknolojileri kullanım seviyesi ( $\beta=0.734$, $\mathrm{t}=8.798, \mathrm{p}<0.05)$; WebQuest kullanımına yönelik alg1 $(\beta=-0.139, \mathrm{t}=-1.677, \mathrm{p}>0.05)$ ve akademik başarı $(\beta=0.734, \mathrm{t}=8.798, \mathrm{p}>0.05)$ olduğunu göstermektedir. Değişkenlerin birlikte ele alındığında, bilgi ve iletişim teknolojileri kullanım seviyesinin WebQuest etkinliklerinin yeterliklerinin anlamlı bir yordayıcısı, akademik başarı ve WebQuest kullanımına yönelik algının anlamlı bir yordayıcısı olmadığı sonucuna ulaşılmıştır. Regresyon analizi sonuçlarına göre, öğretmen adaylarının WebQuest etkinliklerinin 
yeterliklerinin yordanmasına ilişkin regresyon eşitliği (matematiksel model) diğer bir deyişle WebQuest etkinliklerinin yeterliklerini yordayan regresyon denklemi şu şekildedir:

WQ Etkinliklerinin Yeterliliği $=(7.551 * \mathrm{BT}$ kullanım seviyesi $)+(0.319 *$ Akademik başarı)+(-1.647*WebQuest kullanımına yönelik algı)+(15.507)

Modelde yordayıcıların anlamlılığı göz önüne alınırsa regresyon eşitliği aşağıdaki gibi ifade edilebilir:

WQ Etkinliklerinin Yeterliliği= $(7.551 *$ BT kullanım seviyesi $)+(15.507)$

\section{Tartışma ve sonuç}

Son yıllarda bilişim teknolojileri alanındaki hızlı gelişmeler eğitim ortamlarında öğrenme öğretme sürecine teknoloji desteğini zorunlu hale getirmiş ve bilişim teknolojileri ile öğrenme ortamları bütünleşmeye başlamıştır [42]. Öğretmenler için bu teknoloji yumağının içerisinde yer alan öğrencilerle aynı dili konuşmak, gelişen teknolojiye ayak uydurmak ve bu teknolojiden öğretimde yararlanmak son derece önemli bir hal almıştır. Bu noktada akla ilk olarak ögretmen yetiştirme programlarında tedbir almak gelmektedir [43].

$\mathrm{Bu}$ araştırma öncelikle öğretmen adaylarının tasarladıkları WebQuestler incelenmiştir. Araştırmaya katılan 74 öğretmen adayının WebQuest etkinliklerinden aldıkları puanların ortalamasının 43.07, en düşük puan 33, en yüksek puan ise 47 olduğu sonucuna ulaşılmıştır. Tabanlı (2008), bir WebQuestin puanlanması sonucu 40 puan elde edilmesi durumunda WebQuestin yeterli (uygulanabilir) olacağını ifade etmiştir [48]. Araştırmanın verilerine dayanarak öğretmen adaylarının tasarladıkları WebQuestlerin yeterli olduğu söylenebilir. Ulaşılan sonuçlar literatürdeki [21, 30, 31] çalışmalarının sonuçlarına benzerlik göstermektedir. Arhar, Koontz ve Hill (2002) öğretmen adaylarının tasarladıkları WebQuestlerin incelenmesi, bu WebQuestlerin uygulanması ve yaptığı görüşmeler sonucunda öğretmen adaylarının WebQuest etkinliklerini hazırlamada yeterli olduğu sonucuna ulaşmışlardır [30]. Dobson (2003) çalışması da yeterli teknik destek sağlandığında öğretmen adaylarının içerik bilgilerini ve pedagojik becerilerini entegre ederek etkili bir WebQuest hazırlayabildiklerini göstermektedir [31]. Kobak (2013)'e ait çalışmada da öğretmen adaylarının grup olarak öğretim programındaki kazanımlara uygun hazırladıkları WebQuest etkinliklerinin uygulanabilir düzeyde olduğunu göstermektedir [21].

Öğretmen adaylarının bilgi ve iletişim teknolojileri kullanım seviyesinin WebQuest etkinliklerinin yeterliklerinin anlamlı bir yordayıcısı olduğu sonucuna ulaşılmıştır. Elde edilen sonuç, bireylerin geliştirecekleri teknoloji destekli materyallerin yeterliklerinde onların bilgi ve iletişim teknolojileri kullanımı seviyesinin önemli olduğunu göstermektedir. $\mathrm{Bu}$ durum sadece WebQuestlerle sınırlı değildir. Usta (2015) [50] çalışması, bilgisayar kullanım seviyesindeki yetersizliklerin öğretmen adaylarının öğretim materyali tasarlama ve geliştirme aşamalarında güçlük yaşamalarına neden olduğunu göstermektedir. Sevim (2014) [51] çalışması da kendilerini teknoloji kullanımı konusunda yeterli görmeyen öğretmen adaylarının teknoloji destekli öğretim materyalleri yerine, genellikle klasik olarak tanımlanabilecek materyaller geliştirmeyi 
tercih ettiklerini göstermektedir. Çalışma, teknoloji destekli öğretim materyali geliştirme konusunda yaşanılan sıkıntıların disiplinlerarası materyal geliştirme süreci ile aşılabileceğini göstermektedir. Bu süreç, öğretim teknolojilerinin farklı derslerde etkili bir şekilde kullanılabilmesi ve hazırlanmasında her bir ders öğretmeninin bilişim teknolojileri uzmanlarıyla iş birlikli çalışmalar yapmasıyla ilgilidir. Bu açıdan bilgi ve iletişim teknolojileri konusunda yetersiz bireylerin teknoloji destekli materyaller hazırlamasında disiplinlerarası bir materyal geliştirme süreci izlenebilir. Bilgi ve iletişim teknolojilerinin kullanım seviyesi sadece hazırlanan WebQuest etkinliklerinin yeterliklerini etkilememekte aynı zamanda Manning ve Carpenter (2008)'e göre bilgisayar kullanım düzeyinin yeterli olmaması öğrenme ortamlarında WebQuest kullanımının önünde bir engel teşkil etmektedir [49].

Ayrıca bu çalışmada ele alınan değişenler WebQuest etkinliklerinin yeterliklerinin \% 53.5'inin açıklamaktadır. $\mathrm{Bu}$ araştırmada ön görülemeyen diğer değişkenlerin araştırılması, öğretmenlerin teknolojik materyalleri geliştirme konusunda yeterli hale getirilmesi ve buna bağlı teknoloji entegrasyonu önündeki engellerin aşılması açısından önem taşımaktadır.

Araştırmanın sonuçları doğrultusunda araştırmacılara aşağıdaki öneriler getirilmiştir:

- Eğitim fakültelerindeki materyal geliştirme derslerinde sadece ders araç gereçlerinin tasarımı değil aynı zamanda teknoloji destekli öğretim materyallerinin geliştirilmesine yer verilmelidir. Bu tür etkinlikler teknolojinin giderek yaygın bir hal aldığı günümüzde eğitime teknolojinin entegrasyonu kolaylaştıracak, öğrenme ortamlarının önemli bir parçası olan öğretmenler tarafından kazanımlar doğrultusunda nitelikli WebQuestler geliştirilmesine imkan tanıyacaktır.

- Öğretmenlerin bilgi teknolojileri kullanım seviyelerinin artırılması hazırlayacakları teknoloji destekli öğretim materyallerinin yeterliklerini doğrudan etkilemektedir. Bu nedenle hizmet öncesi ve hizmet içi eğitimde öğretmenlere yeni bilgi ve iletişim teknolojileri konusunda eğitimler verilmeli, Milli Eğitim Bakanlığı tarafından bu teknolojileri derslerine entegre etmeleri teşvik edilmelidir. Ayrıca lisans öğretim programları, yeni teknolojilerin kullanımı ve öğrenme ortamlarına entegrasyonu konusunda öğretmen adaylarının yeterliliğini artıracak şekilde gözden geçirilmelidir.

- Bir öğretim materyalinin geliştirilmesindeki önemli unsurlardan biri de öğretmenlerin bu materyali kullanmaya yönelik pozitif bakış açılarıdır. Bu nedenle öğretim materyalini öğretimlerinde kullanmaya yönelik öğretmenlerin bakış açılarının belirlenmesi, negatif bakışların nedenlerinin detaylı olarak incelenmesi ve negatif algıları ortadan kaldırılması için çalışmalar yapılması, teknolojinin öğrenme ortamlarına entegre edilmesini kolaylaştıracaktır.

- $\mathrm{Bu}$ çalışmada öğretmen adaylarının geliştirdiği WebQuest yeterliklerini yordayan değişkenler ortaya koyulmaya çalışılmış, sadece katılımcıların bilgi ve iletişim teknolojileri kullanım seviyelerinin anlamlı bir yordayıcı olduğu sonucuna ulaşılmıştır. WebQuest hazırlama yeterliklerini yordayan diğer değişkenlerin belirlenmesi amaçlı yapılacak bir başka araştırma alanyazına katkı sağlayacaktır. 


\section{Kaynaklar}

[1] Kağızmanlı B.T., Tatar E. ve Zengin Y., Öğretmen adaylarının matematik öğretiminde teknoloji kullanımına ilişkin algılarının incelenmesi, Ahi Evran Üniversitesi Kırşehir Eğitim Fakültesi Dergisi, 14, 2, 349-370, (2014).

[2] Akkoyunlu, B., Educational technology in turkey: past, present and future, Educational Media International, 39, 2, 165-174, (2002).

[3] Koçak Usluel Y., Özmen B. ve Çelen F. K., BİT’in öğrenme öğretme sürecine entegrasyonu ve teknolojik pedagojik içerik bilgisi modeline eleştirel bir bakış, Eğitim Teknolojisi Kuram ve Uygulama, 5, 1, 34-54, (2015).

[4] Mishra, P. ve Koehler, M.J., Technological pedagogical content knowledge: A framework for teacher knowledge, Teachers College Record, 108, 6, 10171054, (2006).

[5] Özmen, B., Usluel, Y., ve Çelen, F.K., Araştırmalarda bilgi ve iletişim teknolojilerinin öğrenme-öğretme sürecine entegrasyonu konusunda var olan durum ve yönelimler, $2^{\text {nd }}$ International Instructional Technologies and Teacher Education Symposium, Afyonkarahisar, Türkiye, (2014).

[6] Shulman, L.S., Those who understand: knowledge growth in teaching. Educational Researcher, 15, 4-14, (1986).

[7] Koh J.H.L., Chai C.S. ve Tsai C.-C., Examining the technological pedagogical content knowledge of Singapore pre-service teachers with a large-scale survey, Journal of Computer Assisted Learning, 26, 563-573, (2010).

[8] Koehler, M. J. ve Mishra, P., What is technological pedagogical content knowledge? Contemporary Issues in Technology and Teacher Education, 9, 1, 60-70, (2009).

[9] Lee, M.H. ve Tsai, C.C., Exploring teachers' perceived self efficacy and technological pedagogical content knowledge with respect to educational use of the world wide web. Instructional Science: An International Journal of the Learning Sciences, 38, 1, 1-21, (2010).

[10] Horzum M., Web pedagojik içerik bilgisi ölçeği’nin türkçeye uyarlaması, İlköğretim Online, 10, 1, 257-272, (2011).

[11] Halat E., Matematik öğretiminde webquestin kullanımına ilişkin öğretmen adaylarının görüşleri, İlköğretim Online, 6, 2, 264-283, (2007).

[12] Faichney, G., WebQuest: A strategy for teaching sose online, ETHOS, 6, 10, 145-168, (2002).

[13] Pamuk, S., Ülken A. ve Dilek N.Ş., Öğretmen adaylarının öğretimde teknoloji kullanım yeterliliklerinin teknolojik pedagojik içerik bilgisi kuramsal perspektifinden incelenmesi, Mustafa Kemal Üniversitesi Sosyal Bilimler Enstitüsü Dergisi, 9, 17, 415-438, (2012).

[14] Dodge B., Some thoughts about webquests [online], (1997). http://webquest.sdsu.edu/about_webquests.html (02 Mart 2012).

[15] Zencirci, İ. ve Asker, E. A $\breve{g}$ araștırması (webquest) tasarlayıcılarının bu etkinliklerin hazırlanması sürecine ve Türkiye'de uygulanabilirliklerine ilişkin görüşleri. Necatibey Eğitim Fakültesi Elektronik Fen ve Matematik Eğitimi Dergisi, 3, 2, 124-148, (2009).

[16] Akçay, A. ve Şahin, A., Bir öğretim stratejisi olarak web macerası (WebQuest), Bilişim Teknolojileri Dergisi, 6, 1, 17-22, (2013).

[17] Gülbahar, Y., Kalelioğlu, F. ve Madran, O., Öğretim ve değerlendirme yöntemi olarak web macerasının kullanışlılık açısından değerlendirilmesi, Ankara Üniversitesi Eğitim Bilimleri Fakülttesi Dergisi, 41, 2, 209-236, (2008). 
[18] Ateşkan, A., Online professional development program for science teachers : a case study. Ph.D Thesis, The Middle East Technical University, Ankara, (2008).

[19] Halat, E. ve Peker, M., The impacts of mathematical representations developed through webquest and spreadsheet activities on the motivation of pre-service elementary school teachers, The Turkish Online Journal of Educational Technology, 10, 2, 259-267, (2011).

[20] Chatel, R.G. ve Nodell, J., WebQuests: teachers and students as global literacy explorers [online], (2002). http://www.eric.ed.gov/PDFS/ED471843.pdf (12 Mayıs 2008).

[21] Kobak, M., Matematik öğretmen adaylarının webquest etkinliklerinde ilişkilendirmelere yer verme düzeyleri ve sürece ilişkin görüşleri, Yüksek Lisans Tezi, Balıkesir Üniversitesi, Fen bilimleri Enstitüsü, Balıkesir, (2013).

[22] Balkı, E. ve Saban, A., Öğretmenlerin bilişim teknolojilerine ilişkin algıları ve uygulamaları: özel esentepe ilköğretim okulu örneği, İlköğretim Online, 8, 3, 771-781, (2009).

[23] Çağıltay, K., Çakıroğlu, J., Çağıltay, N. ve Çakıroğlu, E., Öğretimde bilgisayar kullanımına ilişkin öğretmen görüşleri, Hacettepe Üniversitesi Eğitim Fakültesi Dergisi, 21, 19-28, (2001).

[24] Hope, W.C., Why technology has not realized its potential in schools: A perspective. American Secondary Education, 25, 4, 2-7, (1997).

[25] Mazman, S.G. ve Usluel, Y.K., Bilgi ve iletişim teknolojilerinin öğrenmeöğretme süreçlerine entegrasyonu: modeller ve göstergeler, Eğitim teknolojisi Kuram ve Uygulama, 1, 1, 62-79, (2011).

[26] Usta, E., ve Korkmaz, Ö., Öğretmen adaylarının bilgisayar yeterlikleri ve teknoloji kullanımına ilişkin algıları ile öğretmenlik mesleğine yönelik tutumları, Uluslararası İnsan Bilimleri Dergisi, 7, 1, 1335-1349, (2010).

[27] Yılmaz, M., Üredi, L. ve Akbaşlı, S., Sınıf öğretmeni adaylarının bilgisayar yeterlilik düzeylerinin ve eğitimde teknoloji kullanımına yönelik algılarının belirlenmesi, International Journal of Humanities and Education, 1, 1, 105121, (2015).

[28] Zhao, Y. ve Cziko, G.A., Teacher adoption of technology: A perceptual control theory perspective, Journal of Technology and Teacher Education, 9, 1, 5-30, (2001).

[29] Uşun, S., Özel öğretim teknolojileri ve materyal geliştirme. Ankara: Pegem Akademi, (2000).

[30] Arhar, J., Koontz, T. ve Hill, J., Linking middle childhood teacher candidates to the authentic use of technology in the classroom, Journal of Computing in Teacher Education, 19, 2, 47-53, (2002).

[31] Dobson, M.C., Preparing teachers to use technology: the webquest in the secondary english language arts methods classroom. Ph.D Thesis, Western Michigan University, Kalamozoo, (2003).

[32] Gündüz, Ş. ve Odabaşı, F., Bilgi çağında öğretmen adaylarının eğitiminde öğretim teknolojileri ve materyal geliştirme dersinin önemi, The Turkish Online Journal of Educational Technology, 3, 1, 43-48, (2004).

[33] İşman, A., Baytekin, Ç., Kıyıcı, M. ve Horzum, M.B., İnternet destekli materyal geliştirme dersi alan öğrencilerin interneti kullanma durumları, Uluslararası Katılımlı Açık ve Uzaktan Eğitim Sempozyumu, Anadolu Üniversitesi, Eskişehir, (2002). 
[34] Hofer, M. ve Grandgenett, N., TPACK development in teacher education: a longitudinal study of preservice teachers in a Secondary M.A. Ed. Program. Journal of Research on Technology in Education, 45, 1, 83-106, (2012).

[35] Dodge, B. WebQuest taskonomy: a taxonomy of tasks [online], (2002), http://webquest.sdsu.edu/taskonomy.html, (18 Şubat 2012).

[36] Kundu, R. ve Brain, C., WebQuests: utilizing technology in a constructivist manner to facilitate meaningful preservice learning, Art Education, 59, 2, 6-11, (2006).

[37] Büyüköztürk, Ş., Kılıç Çakmak E., Akgün, Ö.E., Karadeniz, Ş., ve Demirel, F., Bilimsel araştırma yöntemleri (Genişletilmiş 2. Baskı). Ankara: Pegem Akademi, (2008).

[38] Bellofatto, L., Bohl, N., Casey, M., Krill, M. ve Dodge, B., A rubric for evaluating webquests [online], (2001). http://webquest.sdsu.edu/webquestrubric.html (20 Şubat 2012).

[39] Asker, E., A $\breve{g}$ araştırması değerlendirme tablosu (rubric) [online], (2005). http://w3.balikesir.edu.tr/ asker/bdfme_ders_not/webquestrubric.html (12 Şubat 2012).

[40] Kutluca T., Arslan, S. ve Özpınar, İ., Developing a Scale to Measure Information and Communication Technology Utilization Levels. Journal Of Turkish Science Education, 7, 4, 37-45, (2010).

[41] Kobak-Demir, M. ve Gür, H., A perception scale on the use of webquests in mathematics teaching: A study of scale development, Educational Research and Reviews, 11, 20, 2079-2087, (2016).

[42] Ekici, E., Taşkın Ekici, F. ve Kara, İ., Öğretmenlere yönelik bilişim teknolojileri öz-yeterlik algısı ölçeğinin geçerlik ve güvenirlik çalışması, Pamukkale Üniversitesi Eğitim Fakültesi Dergisi, 31, 1, 53-65, (2012).

[43] Başal A., English language teachers and technology education, Journal of Theory and Practice in Education, 11, 4, 1496-1511, (2015).

[44] Aslan, B. ve Görgen, İ., Orta okul ve lise kademelerinde çalışan branş öğretmenlerin öğretim teknoloji ve materyallerine farkındalık düzeyi. International Periodical for the Languages, Literature and History of Turkish or Turkic, 10, 11, 173-186, (2015).

[45] Gömleksiz, M.N., Kan, A.Ü. ve Serhatlığlu B., Öğretim teknolojileri ve materyal geliştirme dersinin materyal hazırlama ilkelerini kazandırmadaki etkililiğine ilişkin öğretmen adaylarının görüşleri, Elektronik Sosyal Bilimler Dergisi, 9, 32, 1-16, (2010).

[46] Doering A., Hughes, J.E. ve Huffman, D., Preservice teachers: are we thinking with technology? Journal of Research on Technology Education, 35, 3, 342361, (2003).

[47] Erdemir, N, Bakırcı, H. ve Eyduran, E., Öğretmen adaylarının eğitimde teknolojiyi kullanabilme özgüvenlerinin tespiti, Türk Fen Eğitimi Dergisi, 6, 3, 99-108, (2009).

[48] Tabanlı, S.G., Bilişim teknolojilerinin temelleri dersinin öğretiminde yapılandırmacılık uygulaması: webquest tekniğine ilişkin öğrenci görüşleri, Yüksek Lisans Tezi, Ege Üniversitesi, Fen Bilimleri Enstitüsü, İzmir, (2008).

[49] Manning, J.B. ve Carpenter, L.B., Assistive technology webquest: improving learning for preservice teachers, TechTrends, 52, 6, 47-52, (2008).

[50] Usta, E., Öğretmen adaylarının öğretim materyalleri geliştirme süreçlerinin görsel ve mesaj tasarımı ilkeleri açısından incelenmesi, Gazi Eğitim Bilimleri Dergisi, 1, 1, 1-14, (2015). 
[51] Sevim, O. Disiplinlerarası materyal geliştirme sürecinin Türkçe öğretmen adaylarının öğretim tasarımı başarılara ve üst bilişsel farkındalıklarına etkisi, Turkish Studies-International Periodical For The Languages, Literature and History of Turkish or Turkic, 9, 9, 897-913, (2014). 


\section{EK 1 Örnek WebQuest Etkinliği}

\section{SERA ETKISİ: INGIILTERE SULAR ALTINDA MI KALACAK?}

\section{GíRiș}

TANRIM! INGILTERE SULAR ALTINDA MI KALACAK?

Atmosferdeki gazlar yeryüzünden uzaya yayılan uzun dalga boylu ışığı önce soğurur daha sonra tekrar yayar. Sera gazları Dünya'dan uzaya yayılan ısının (kızılötesi ışığın) bir kısmını geri yansıtarak Dünya'nın ısınmasına neden olur. Bu olaya sera etkisi denir.

Artan sıcaklıklar buzdağlarını ve buzulları etkilerse, Kuzey Kutbu buzul başlı̆ı erime tehlikesiyle karşılaşır mı ve okyanuslar yükselir mi? Bu gerçekleşebilir, ancak hiç kimse bunun ne zaman olacağını bilmiyor.

(https://vimeo.com/2316052)

PEKİ ŞIMDİ NE OLACAK? EĞER BİR ÖNLEM ALINMAZSA İNGILTERE GÖRÜNMEYECEK Mi?

\section{GÖREV}

Kömür ve yağ gibi yakıta dönüssen fosillerin yanmasıyla atmosfere karbondioksit yayılır. Bu belki, kısmen biyolojik reaksiyonlarla ortadan kaldırlabilir. Fakat karbondioksitin konsantrasyonu giderek artmaktadır. Bu artış dünyanın ortalama sıcaklığında artışa neden olur.

Eğer dünyanın ortalama sıcaklığı, 1980 yılındaki değerinden $6^{\circ} \mathrm{C}$ daha artarsa, bu buzullarda ve kış sıcaklığında önemli bir etki yapacaktır. Buzullardaki kutuplar eridiğinde çok fazla su sıkıntısı olacak ve bu akıntıyla birçok kara suyun altında kalacaktır. Dağların zirvesi dışında İngiltere görünmeyecektir.

Yukarıdaki problem durumuyla ilgili verileri bul. Bu verilere ilişkin bir model oluștur. Dünyanın sıcaklı̆ğ 1860 'daki değerlerin $7^{\circ} \mathrm{C}$ üstünde olduğu yılı tahmin etmek için bunu kullanın ve problemi çözmek için 4 kişilik grup halinde çalışınız, projenizi TÜBİTAK a sununuz.

\section{SÜREÇ BASAMAĞI}

Bu projenin başarılı bir şekilde işlemesi için projeyi grup olarak yürütmeniz gerekmektedir. Projenin başarılı olabilmesi için size verilen roldeki kimliğin olaya bakış açısını çok iyi anlamanız ve sınıfta bu bakış açısını çok iyi ve tutarlı bir şekilde yansıtmanız beklenmektedir. Projenin başarılı bir şekilde oluşması için aşağıda belirtilen maddelere uyarak projeyi tamamlamanız gerekmektedir. 1- İlk olarak grup üyelerinin başarılı bir proje oluşturabilmek için sorumlu olduğu görevi en iyi şekilde araştırması gerekir. Öyle ki grup üyeleri arasında bile kim en iyisini yapacak diye rekabet ortamı oluşmalıdır. Uzmanların sera etkisi hakkında gerekli olacak önbilgiye sahip olması gerekli, bu yüzden herkes sorumlu olduğu görev hakkında bilgi edinebilmek için araştırma yapmalı ya da konuyla ilgili diğer uzmanlara sorular sorarak bilgiler edinmelidir. 2- Araştırmalar yapılıp, gerekli önbilgiye sahip olduktan sonra başarılı olabilmeleri için hangi alanlarda neler yapabiliriz üzerine tartışıp; "sera etkisi, sera etkisine sebep olan gazlar, sera etkisi nasıl önlenebilir “ sorularına cevaplar arayacaksinız.

3- Her grup üyesi kendi alanlarında yaptıkları araşıırmaların sonuçlarını grup arkadaşlarına sunarak fikir alışverişi yapıp, değerlendirmelerde bulunacak. Herkes İngiltere'nin ne zaman sular altında kalacağının bulunmasına ilişkin maksimum katkıyı nasıl yapabilirim düşüncesi içinde olmalı. Aksi takdirde projede sorunlar çıkabilir.

4- Değerlendirmeden sonra herkes sorumlu olduğu görev için yapacakları işlerin son halini grup üyelerine sunacak, projeyi sekteye uğratabilecek durumların hepsini göz önünde bulunduracaksınız. Fikir alışverişi esnasında her grup üyesi, grup arkadaşları tarafından değerlendirilip, projenin son haline ulaşılacaktır.

5- Çıkarımları elde ettikten sonra verilerin hepsi ortak bir paydada toplanacak ve nihayetinde ürün ortaya çıkmış olacak. En sonunda da projeler TÜBİTAK'a anlatılıp rapor halinde sunulacaktır.

\section{Çevre Mühendisi:}

Senin görevin aşağıdaki soruları cevaplamaktır.

Sera etkisi nedir? Sera gazları nelerdir? Sera etkisi küresel ısınmayı nasıl etkiler? İnsanların hangi 
faaliyetleri küresel ısınmayı etkiler? Hava kirliliğini önlemek için alınabilecek önlemler nelerdir?

Aşağıdaki kaynaklardan faydalanınız.

http://cevremuhendisligi.org/index.php?option=com content\&view=article\&id=20:sera-etkisi-ve-

kuresel-isinma\&catid=4:bunlari-biliyormusunuz $\&$ Itemid $=7$

http://www.bilimgenc.tubitak.gov.tr/video/sera-etkisi

https://vimeo.com/122154666

https://books.google.com.tr/books?id=P8oYnjpwZR8C\&pg=PA155\&lpg=PA155\&dq=ingiltere\%27nin+ sular+alt\%C4\%B1nda+kalmas\%C4\%B1\&source=bl\&ots=MRmm2Cfb9m\&sig=9NuhZpYMHfFT3ocIJ 2kEUcHT k\&hl=tr\&sa=X\&ved=0CFEQ6AEwCWoVChMIiu9gvfVyAIVRYgsCh1aDAYr\#v=onepage \&q=ingiltere'nin\%20sular\%20alt\%C4\%B1nda\%20kalmas\%C4\%B1\&f=false

\section{Meteoroloji Mühendisi:}

Senin görevin aşağıdaki verilere ulaşmaktır.

Yukarılara ilişkin 1880-1980 yılları arasındaki Dünyadaki sıcaklık artışını veren verilere ulaşınız.

http://www.emo.org.tr/ekler/4e17d99a1e885b3_ek.pdf?dergi=486

http://www.mgm.gov.tr/cocuklar/kitapmeteoroloji.aspx?s=kureselisinma

http://www.mgm.gov.tr/files/iklim/iklimetkileri.pdf

\section{İstatistikçi:}

Senin görevin aşağıdaki görevleri yerine getirmektir.

Problem durumu ile ilgili bilgi toplayı, örnekleme planı hazırlayınız. Toplanan bilgileri sınıflandırınız ve aralarındaki ilişkiyi belirleyip, bilgileri tablolara, grafiklere işleyiniz. Problemin çözümüne ilişkin excel programından faydalanınız.

Aşağıdaki kaynaklardan faydalanınız.

http://www.mgm.gov.tr/cocuklar/kitapmeteoroloji.aspx?s=kureselisinma http://www.uzmantv.com/konu/excel-ile-hesaplama http://www.cerezforum.net/konu/matematikte-tablo-ve-grafik-nedir.53314/

\section{Matematik Mühendisi:}

Senin görevin aşağıdaki görevleri yerine getirmektir.

Probleme dayalı toplanan veriler ışı̆ıında matematiksel modelleri kurunuz, çözünüz ve yorumlayınız.

Problemin çözümü için yöntemler geliştiriniz.

Aşağıdaki kaynaklardan faydalanınız.

http://bilgiyelpazesi.com/egitim_ogretim/konu_anlatimli_dersler/matematik_dersi_ile_ilgili_konu_anlati $\underline{\text { mlar/logaritma_cesitleri_ozellikleri.asp }}$

http://www.slideserve.com/courtney/matematiksel-modelleme

\section{KAYNAKLAR:}

http://www.bilimgenc.tubitak.gov.tr/video/sera-etkisi

https://vimeo.com/2316052

https://vimeo.com/122154666

http://www.mgm.gov.tr/cocuklar/kitapmeteoroloji.aspx?s=kureselisinma

http://cevremuhendisligi.org/index.php?option=com content\&view=article\&id=20:sera-etkisi-ve-

kuresel-isinma\&catid=4:bunlari-biliyormusunuz \&Itemid=7

http://www.mgm.gov.tr/files/iklim/iklimetkileri.pdf

https://books.google.com.tr/books?id=P8oYnjpwZR8C\&pg=PA155\&lpg=PA155\&dq=ingiltere\%27nin+ sular+alt\%C4\%B1nda+kalmas\%C4\%B1\&source=bl\&ots=MRmm2Cfb9m\&sig=9NuhZpYMHfFT3ocIJ 2kEUcHT_k\&hl=tr\&sa=X\&ved=0CFEQ6AEwCWoVChMIiu9gvfVyAIVRYgsCh1aDAYr\#v=onepage \&q=ingiltere'nin\%20sular\%20alt $\% \mathrm{C} 4 \% \mathrm{~B} 1 \mathrm{nda} \% 20 \mathrm{kalmas} \% \mathrm{C} 4 \% \mathrm{~B} 1 \& \mathrm{f}=$ false

http://www.uzmantv.com/konu/excel-ile-hesaplama

http://www.cerezforum.net/konu/matematikte-tablo-ve-grafik-nedir.53314/

http://bilgiyelpazesi.com/egitim_ogretim/konu_anlatimli_dersler/matematik_dersi_ile_ilgili_konu_anlati mlar/logaritma_cesitleri_ozellikleri.asp

http://www.slideserve.com/courtney/matematiksel-modelleme 


\section{SONUÇ}

Günümüzde tüm Dünya'da şehirleşme hareketleri, kırsal kesimden olan göçler ile birlikte hızlanmakta, nüfus yoğunluğunun aşırı bir şekilde artması ve değişen yaşam standartları sonucu da daha çok sanayi üretimine ihtiyaç duyulmaktadır. Bunların sonucunda da artan şehirleşme, özellikle sanayi ve yerleşim bölgelerinden çıkan sera gazları ile çevre ve atmosferin büyük miktarda kirlenmekte ve küresel ölçekte havanın ısınma eğilimi yükselmektedir. Böylece, canlı küreden (biyosferden) yukarı atmosfere (stratosfere) kadar olan kısım başta olmak üzere, günümüzde dünya atmosferinin kirlenmesi giderek artmaktadır. Bütün bunlar, doğayı tahrip ederek kentlerin iklimini değiştirmek ile birlikte su, kara ve havadaki yaşamı tümüyle tehdit eden çevre problemlerini de beraberinde getirmektedir.

Bu proje sonunda günümüz şartlarında, sera gazları, atmosferin sera etkisi, sera etkisini önleme yolları, günümüzde sera etkisine bağlı iklimde gözlenen değişimler, tahmin ve beklentiler gibi konuların önemi vurgulanmıştır. Herkes sorumlu olduğu görev hakkında bilgi edinebilmek için araştırma yapmış ya da konuyla ilgili diğer uzmanlara sorular sorarak bilgiler edinmiş bulunmaktasınız.

Bu verilere ilişkin bir model oluşturdunuz. Dünyanın sıcaklığı 1860 ' daki değerlerin $7^{\circ} \mathrm{C}$ üstünde olduğu yıl verilere dayanılarak tahmin etmiş bulunmaktasınız.

Gerçekten böyle bir problemin gerçekleşme durumunu ve eğer gerçekleşirse alınabilecek önlemleri grup üyeleri çalışmaları sonucu görmüştür.

Ortaklarla iş yürütmenin zorluğunu ancak planlı ve düzenli şekilde olayların gitmesiyle işlerin eğlenceli ve başarılı bir şekilde ilerleyeceğini öğrenmiş bulunmaktasınız.

Genellikle fikirler tek başına olunca düzgün işler ancak işin içine farklı kişilerden de düşünceler gelince işler biraz karışır. Diğer taraftan da fikirler paylaşılmazsa, etkilenme olmazsa; yaratıcılık, çekicilik ve inandırıcılık olmaz. Sonuçta herkes aynı fikir üzerinde birleşirse de ortaya çok iyi bir ürün çıkar. Artık siz bunların tamamını biliyorsunuz...

\section{DEĞERLENDIRME}

Değerlendirme işlemi gerçekleştirilirken hem bireysel hem de grup değerlendirilmesi yapılacaktır.

\begin{tabular}{|c|c|c|c|c|}
\hline & Zayıf(1) & $\operatorname{Orta}(2)$ & İyi(3) & Puan \\
\hline $\begin{array}{l}\text { Verilen } \\
\text { kaynaklardan } \\
\text { yararlanma } \\
\end{array}$ & $\begin{array}{l}\text { Verilen } \\
\text { kaynaklardan } \\
\text { yararlanılmamış. }\end{array}$ & $\begin{array}{l}\text { Verilen kaynaklardan } \\
\text { yeterli düzeyde } \\
\text { yararlanmamış. }\end{array}$ & $\begin{array}{l}\text { Verilen kaynaklardan } \\
\text { yararlanılmış. }\end{array}$ & \\
\hline $\begin{array}{l}\text { İnternetten ve } \\
\text { bilgisayar } \\
\text { programlarında } \\
\text { n faydalanma }\end{array}$ & $\begin{array}{l}\text { İnternetten ve } \\
\text { bilgisayar } \\
\text { programlarından } \\
\text { hiç } \\
\text { faydalanılmamış. }\end{array}$ & $\begin{array}{l}\text { İnternetten ve } \\
\text { bilgisayar programları } \\
\text { kullanılmış ancak } \\
\text { yeterli düzeyde değil. }\end{array}$ & $\begin{array}{l}\text { İnternetten ve } \\
\text { bilgisayar } \\
\text { programlarından yeterli } \\
\text { düzeyde faydalanılmış. }\end{array}$ & \\
\hline $\begin{array}{l}\text { Grafik çizme ve } \\
\text { tablo oluşturma }\end{array}$ & $\begin{array}{l}\text { Grafik çizilmemiş, } \\
\text { tablo } \\
\text { oluşturulmamıştır }\end{array}$ & $\begin{array}{l}\text { Grafik çizimi ve tablo } \\
\text { oluşumu yanlış } \\
\text { yapılmıştır. }\end{array}$ & $\begin{array}{l}\text { Grafik ve tablolar } \\
\text { doğru olarak } \\
\text { oluşturulmuştur. }\end{array}$ & \\
\hline $\begin{array}{l}\text { Matematiksel } \\
\text { modelleme } \\
\text { oluşturma } \\
\end{array}$ & $\begin{array}{l}\text { Model } \\
\text { oluşturulmamış. }\end{array}$ & $\begin{array}{l}\text { Doğru şekilde model } \\
\text { oluşturulmamış. }\end{array}$ & $\begin{array}{l}\text { Modellemeler doğru } \\
\text { bir şekilde } \\
\text { oluşturulmuş. }\end{array}$ & \\
\hline $\begin{array}{l}\text { İş birlikli } \\
\text { çalışma }\end{array}$ & $\begin{array}{l}\text { Grup üyeleri } \\
\text { birbirinden } \\
\text { bağımsız hareket } \\
\text { etmiştir. }\end{array}$ & $\begin{array}{l}\text { İş birlikli çalışma tam } \\
\text { anlamıyla yerine } \\
\text { getirilmemiştir. }\end{array}$ & $\begin{array}{l}\text { Grup üyeleri arasında } \\
\text { tam bir iş birliği } \\
\text { gerçekleşmiştir. }\end{array}$ & \\
\hline $\begin{array}{l}\text { Bireysel } \\
\text { sorumlulukları } \\
\text { yerine getirme }\end{array}$ & $\begin{array}{l}\text { Bireysel } \\
\text { sorumlulukları } \\
\text { yerine } \\
\text { getirmemiştir. }\end{array}$ & $\begin{array}{l}\text { Bireysel sorumlulukları } \\
\text { eksik olarak yerine } \\
\text { getirmiştir. }\end{array}$ & $\begin{array}{l}\text { Her birey üzerine } \\
\text { düssen sorumlulukları } \\
\text { eksiksiz olarak yerine } \\
\text { getirmiştir. }\end{array}$ & \\
\hline $\begin{array}{l}\text { Projenin gerçek } \\
\text { hayata yansıması }\end{array}$ & $\begin{array}{l}\text { Projenin gerçek } \\
\text { hayatta olma } \\
\text { olasılığ1 yok gibi. }\end{array}$ & $\begin{array}{l}\text { Projenin gerçek hayata } \\
\text { uygulanabilirliği } \\
\text { yüksek. }\end{array}$ & $\begin{array}{l}\text { Proje bire bir gerçek } \\
\text { hayatla örtüşüuyor. }\end{array}$ & \\
\hline Sunum & $\begin{array}{l}\text { Hazırlanmış ama } \\
\text { çalışılmamış }\end{array}$ & $\begin{array}{l}\text { Hazırlanmış, orta } \\
\text { seviyede anlatılmış, ses } \\
\text { tonu yetersiz, zamanı }\end{array}$ & $\begin{array}{l}\text { İyi hazırlanmış, } \\
\text { kurallarına uyulmuş, } \\
\text { ses tonu yeterli }\end{array}$ & \\
\hline
\end{tabular}




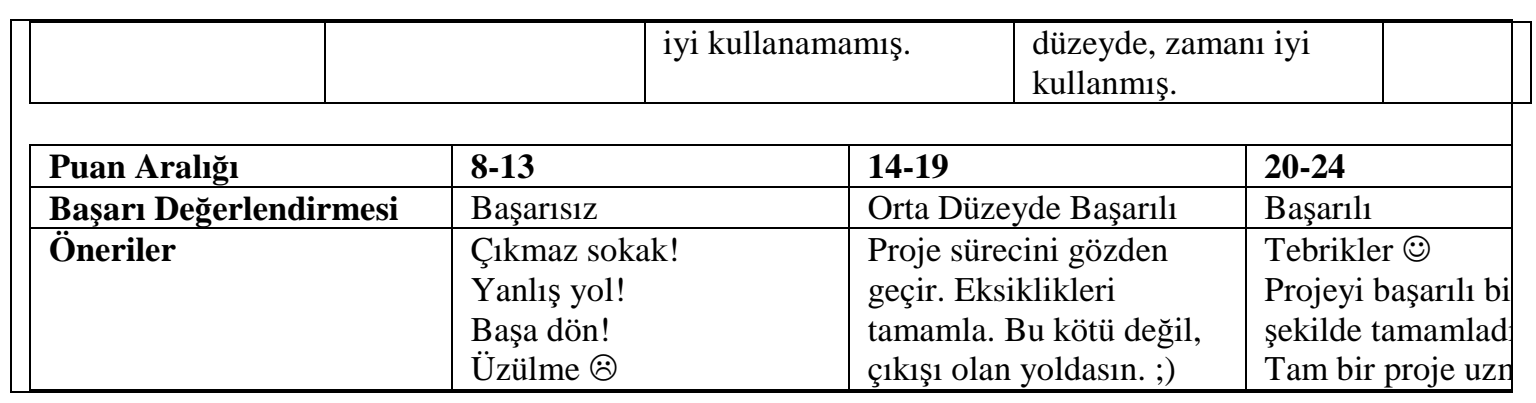

